chondrial conversion of cholesterol to 5-pregnenolone is suggested as a rate-limiting step influenced by anterior pituitary trophins. There are probably similar mechanisms in the placenta. This organ, which contains a very active sulphatase system in the microsomes, can convert androgenic steroids (from the maternal and foetal adrenal cortex) into phenolic oestrogens.

The last part of the book deals with current concepts of the mechanism of action of hormones. The genetic control of metabolism, protein biosynthesis and enzyme activity in cells are described and it is suggested that hormones may regulate a metabolic process essential to both replication of DNA and the synthesis of messenger RNA. In many tissues hormonal regulation is essential to cell function and replication, but it is possible that different types of hormones regulate cell function by different mechanisms. There is yet no clear evidence as to the mechanism of action of hormones at the cellular level.

May ReED

\section{PARASITIC PROTOZOA}

\section{Parasitic Protozoa}

By J. R. Baker. (Hutchinson University Library: Biological Sciences.) Pp. 176. (Hutchinson: London, November 1969.) Hardback $33 s$; paperback $14 s$.

InTERest in parasitic Protozoa has increased rapidly in recent years, but there has been a notable lack of a cheap, up to date textbook suitable for a newcomer to the field. The choice has lain between books specializing in parasites of either medical or veterinary importance and books of general protozoology which are usually expensive and contain more information than is needed. Dr Baker's new book, which is based on a course of lectures given at the London School of Hygiene and Tropical Medicine, admirably fills this gap. It is aimed primarily at the medical and veterinary student, but includes much that should appeal to the undergraduate and postgraduate student of biology.

Most of the major groups of Protozoa contain parasitic forms; the Sporozoa are exclusively parasitic. Dr Baker defines parasitism in a broad sense to include organisms which might otherwise be classified as commensals. After an introductory chapter on taxonomy and possible courses of evolution, he gives a brief but comprehensive summary of protozoan anatomy and physiology. It is not his intention to dwell on ultrastructure and biochemistry because, as he points out, these aspects have been covered fully in several recent review papers. Much of the book is a systematic account of the parasites of economic importance, with sections on pathogenesis, diagnosis and treatment. Brief accounts are given of most other important parasites, although some, for example, the parasitic members of the Phytomastigophorea, are omitted entirely. The book has a well selected reference list, and is sufficiently up to date to include, for example, the now nomenclature of trypanosome forms and the recent discovery that certain free-living amoebae such as Hartmanella are potential parasites. Many details have been set out as tables, which has made for easier reading of the text. All the illustrations are clear blackand-white line-drawings, most of which are original. Colour diagrams would have been more instructive in certain cases, for example, the malaria parasites, but presumably it was impossible to include these in a book of this price. There is also a remarkably large number of informative footnotes, some of which could have been incorporated more appropriately into the main text. The chapter on trypanosomes and related parasites can be especially recommended for its clear guidance through the often bewildering complexity of species with similar morphology. The final section of the book is a useful summary of the techniques in common use for studving parasitic Protozoa, which should be appreciated particularly by teachers and demonstrators.

This book, therefore, is an interesting newcomer to the useful "Hutchinson University Library" series. It is a pity that the price of these volumes has more than doubled in the past six years, but the paperback edition is still an excellent buy for the hard-up student.

D. WALLIKER

\section{AROUSAL MECHANISMS}

\section{The Neurological Basis of Motivation}

An Enduring Problem in Psychology. Edited by Stephen E. Glickman and Peter M. Milner. (An Insight Book.) Pp. viii +286 . (Van Nostrand: New York and London, November 1969.) $\$ 2.75 ; 26 s$.

THIs attractive little booklet has a slightly misleading title. Motivation is not the best word to use to convey what it is all about and reference has to be made to the second paragraph of the preface to find the editors' definition. They say that the book is really concerned with arousal mechanisms, mechanisms which regulate certain drives such as hunger and thirst, and is also concerned with the processes connected with positive and negative reinforcement systems.

With these aims, the editors have collected a number of very interesting papers, all of which can be regarded as classics in their respective fields, and in this way the collection forms a very useful reference for those wanting to have under one cover the basis for further reading. All the papers have been published in journals within the past 10 years although most of them were published in the years 1960 to 1963 .

The standard of reproduction of the figures suffers from the limitations of the paper used and, while line diagrams are clear, half tone reproductions have lost considerably in quality. This is inevitable, but anybody who wishes to see the original pictures has only to look back at the original source of publication.

As a compendium for students, even at the later stages of a degree course, it is an excellent investment and it will not only serve the needs of those psychology students who wish to look more closely at the neurological basis of experimental findings, but it should also interest students of other disciplines, physiology in particular, in the behavioural aspects of the central nervous system.

\section{J. L. MALCOLM}

\section{Correspondence}

Fingerprint Classification

SIn,-R. Clerici suggests a fingerprint classification scheme that could be usefully adopted in anthropological genetical and clinical investigations of fingerprints, and quite naturally he mentions only very briefly fingerprint retrieval for identification purposes (Nature, 224, 779; 1969).

I would like to mention that the Home Office Scientific Development Branch has been funding research with a viow to finding a method of computerizing the fingerprint retrieval of scene-of-crime marks. A special management committee, including experts in computer science and pattern recognition, was established in 1966 and sought advice from leading scientists and fingerprint experts. Research teams in industry were asked to investigate various possible approaches (optical, topological, geometrical, etc.). Most techniques have proved inadequate because they have not been able to cope with the rheological distortions commonly found in scene-of-erime marks. Variations between impressions from the same finger under different stresses are larger than at first 